\title{
Molecular Mechanisms of Preeclampsia
}

\author{
N. Vitoratos, D. Hassiakos, and C. Iavazzo \\ 2nd Department of Obstetrics and Gynecology, University of Athens, Aretaieion Hospital, 11528 Athens, Greece \\ Correspondence should be addressed to C. Iavazzo, christosiavazzo@hotmail.com
}

Received 11 October 2011; Accepted 19 December 2011

Academic Editor: Maria Kyrgiou

Copyright () 2012 N. Vitoratos et al. This is an open access article distributed under the Creative Commons Attribution License, which permits unrestricted use, distribution, and reproduction in any medium, provided the original work is properly cited.

Preeclampsia is one of the leading causes of maternal morbidity/mortality. The pathogenesis of preeclampsia is still under investigation. The aim of this paper is to present the molecular mechanisms implicating in the pathway leading to preeclampsia.

\section{Introduction}

Preeclampsia is one of the leading causes of maternal morbidity/mortality and preterm delivery worldwide [1]. It is a syndrome defined by the onset of hypertension $(\geq 140 / \geq 90 \mathrm{mmHg})$ and proteinuria $(\geq 0,3 \mathrm{gr} / 24 \mathrm{~h})$ after 20 weeks of gestation in a previously normotensive woman that also may be associated with myriad, other signs and symptoms, and often with subnormal fetal growth [2, 3]. Most commonly, preeclampsia occurs in healthy nulliparous women. However, multiparous pregnant women with a new partner have an increased risk of preeclampsia similar to that of nulliparous women [4]. Women with a history of preeclampsia in a prior pregnancy are at increased risk of developing preeclampsia in future pregnancies [5]. A history of preeclampsia in the father's mother also confers an increased risk [6]. Several medical conditions, such as chronic hypertension, diabetes mellitus, renal disease, and hypercoagulable states are associated with increased preeclampsia risk [7, 8]. Additionally, obstetrical conditions with increased placental mass increase the risk of preeclampsia. These include hydatidiform mole [9] and multifetal gestation [10].

Delivery of the placenta remains the only known treatment for this clinical disease, suggesting that the placenta is the principal contributor to the pathogenesis of preeclampsia. It is well known that the first step for the development of preeclampsia is the inadequate placental cytotrophoblast invasion, impaired trophoblast invasion, and inadequate maternal spiral artery remodeling which results in placental ischemia and hypoxia. However, placental ischemia does not always generate the clinical symptoms of preeclampsia. Many molecular mechanisms are contributed to the pathogenesis of preeclampsia. Altered angiogenic balance, systemic inflammation, dystregulation of renin-angiotensin system, and placental hypoxia and ischemia are mechanisms which contribute to the pathogenesis of pre-eclampsia, although it is unknown whether the mechanisms act independently or have synergistic effects.

\section{Altered Angiogenic Balance}

2.1. Angiogenic Factors. A variety of angiogenic factors are produced from the human placenta. The most important between them are the vascular endothelial growth factor (VEGF) and the placental growth factor (PIGF) [11]. VEGF is an endothelial-specific mitogen that plays a key role in promoting angiogenesis. VEGF stabilizes endothelium in mature blood vessels [12]. VEGF'S activities are mediated primarily by its interaction with two high-affinity receptors tyrosine kinases-kinase-insert domain region (KDR or VEGF R-2) and fms-like tyrosine kinase-1 or flt-1. Both receptors are expressed on vascular endothelial cell surface [13]. PIGF is also an angiogenic growth factor that is thought to amplify VEGF signalling by displacing VEGF from the flt-1 receptor and allowing it to bind to the more active kinase-insert domain (KDT) receptor $[14,15]$.

Recent research has shown that soluble flt- 1 is released by the placenta into the maternal circulation and, that is, contributes to the hypertension, proteinuria, and endothelial cell dysfunction associated with preeclampsia [16]. sflt-1 antagonizes both VEGF and PIGF by binding them in 
the circulation and preventing interaction with their endogenous receptors $[17,18]$. New variants of sflt-1 have been discovered such as sflt1-14, which is also a potent VEGF inhibitor $[19,20]$. The level of SFLt-1 in the plasma of women with preeclampsia is elevated and that of VEGF is diminished in comparison with that of women with complicated pregnancies [21]. Furthermore, administration of sflt- 1 to rats resulted in elevated blood pressure and proteinuria, indicating that excessive placenta-derived sflt-1 max contributes to preeclampsia [21].

Factors responsible for excessive production of self- 1 in preeclampsia have not been identified. However, recently it has been found that angiotensin II type 1 (AT) receptor autoantibodies which occur in women with preeclampsia contribute to increased production of sflt-1. Thus, IgG from women with preeclampsia stimulates the synthesis and secretion of sflt- 1 , via $\mathrm{AT}_{1}$ receptor activation in human placental villous explants and human trophoblast cells. Another factor which contributes to increased production of sflt- 1 is the hypoxic placenta [22]. Under other pathophysiological conditions such as cancer and hypoxia which generally stimulates angiogenic signalling, it remains poorly understood why hypoxic placenta produces the molecules that suppress angiogenesis in preeclampsia [23].

Soluble endoglin is another antiangiogenic protein, which acts to get it with sflt- 1 to induce a severe preeclampsia-like syndrome in pregnant rats. Circulating soluble endoglin levels increased markedly beginning from 2 to 3 months before the onset of preeclampsia. An increased level of soluble endoglin was usually accompanied by an increased ratio of sflt-1 [24].

Experiments data have shown that VEGF stimulates the production of both nitric oxide $(\mathrm{NO})$ and $\mathrm{PGI}_{2}$ [25]. On the other hand, a high concentration of asymmetric dimethylarginine (ADMA), an endogenous inhibitor of endothelial nitric oxide synthase, has been found in preeclamptic women [26].

Women with bilateral notches who later developed preeclampsia had a striking elevation in the concentration of the NO synthase inhibitor [27].

ADMA is normally metabolized to citrulise through the action of dimethylarginine-dimethylaminohydrolase I, II (DDAH I, II). Oxidative stress seen in preeclampsia diminishes the action of the alone enzymes leading to high concentration of ADMA [27].

\section{The Role of Relaxin in Preeclampsia}

Relaxin is produced by the corpus luteus of the ovary and rises early in pregnancy, and chorionic gonadotropin produced by the placenta is a major stimulus for relaxin secretion during pregnancy.

Relaxin has renal vasodilatory effect [28], and it also diminishes the relaxin vasoconstrictor response to angiotensin II. Moreover, reduced myogenic reactivity of small renal arteries is observed after relaxin administration [29, 30]. Recently, it has been proposed that relaxin via relaxin receptor upregulates vascular gelatinase activity during pregnancy, contributing to renal vasodilation through activation of endothelial endothelin $\mathrm{B}\left(\mathrm{ET}_{\mathrm{B}}\right)$ receptor which activates nitric oxide synthase III and the production of NO [31]. Thus, increased vascular gelatinase activity by relaxin is thought to be a proximal step in the vasodilatory pathway of pregnancy [32].

Circulating levels of immunoreactive relaxin have been reported to be similar in women with preeclampsia and normal pregnancy [33]. However, whether circulating relaxin bioactivity may be deficient during the disease is uncertain [34]. Furthermore, mutations or polymorphisms of the $\mathrm{ET}_{\mathrm{B}}$ receptor or of endothelial NO synthase that reduce activity may predispose a woman to preeclampsia by impairing trophoblast invasion on the one hand or by compromising maternal endothelial behaviour on the other $[35,36]$.

\section{Inflammatory Cytokines in the Pathophysiology of Preeclampsia}

Reduced uterine perfusion during pregnancy is an important initialling event in preeclampsia. Inflammatory cytokines are thought to link placental ischemia with cardiovascular and renal dysfunction [37]. In normal pregnancy TNF- $\alpha$ is low in the first trimester and subsequently increases with advancing gestation age [38]. Some studies report higher TNF- $\alpha$ levels in women with established preeclampsia $[39,40]$. Increased levels of TNF- $\alpha$ antigen and mRNA have been described in placental tissue from preeclamptic women [41].

Because TNF- $\alpha$ may impair insulin signalling, inhibit lipoprotein lipase, induce PAI-1, and directly contribute to endothelial dysfunction, this cytokine may be involved in the pathogenesis of preeclampsia [42].

There are also findings showing that chronic infusion of IL-6 into normal pregnant rats stimulates the reninangiotensin system (RAS) [37].

Natural killer (NK) cells, dendritic cells, and macrophages are mediators of innate immunity. Macrophages and dendritic cells are the major antigen-presenting cells in the uterus, and they facilitate adaptation of the immune response to prevent rejection of the embryo [43].

Several studies have found a statistically significant increase in macrophages and dendritic cells in preeclamptic placentas compared to placentas from normotensive pregnancies $[43,44]$. An increase in the concentration of cytokines, molecules capable of recruiting macrophages, and dentritic cells has also been found in preeclamptic placentas [44].

The increased presence of cytokines, macrophages, and dendritic cells in preeclamptic placentas supports the hypothesis that an inflammatory milieu presents in women with preeclampsia [44].

\section{Activation of Renin-Angiotensin System (RAS)}

Renin-angiotensin system is one that controls blood pressure [45]. The expression of rennin mRNA was detected in human deciduas, macrophages, chorioamniotic membrane, and vascular smooth muscle cells [46]. 
Angiotensin II receptor type I ( $\left.\mathrm{AT}_{1}\right)$ was shown to be localized both in villous and extravillus trophoblasts, and this $\mathrm{AT}_{1}$ responds to exogenously administrated angiotensin II [47].

The circulating level of angiotensin II increases as the pregnancy advances [48]. In preeclampsia, the circulating level of angiotensin is rather decreased [49], despite the fact that the vascular sensitivity to angiotensin is elevated in hypertensive pregnant women.

The $\mathrm{AT}_{1}$ receptor gene expression was higher in placenta than in deciduas for both normal and preeclamptic women. However, the deciduas of preeclamptic women has a significantly higher $\mathrm{AT}_{1}$ receptor gene expression than normal pregnant women [50]. It has been found that the gene encoding the $\mathrm{AT}_{1}$ receptor was upregulated in the deciduas of preeclamptic women but not in normal control [51]. Circulating agonistic autoantibodies directed at the angiotensin II type 1 receptor $\left(\mathrm{AT}_{1}-\mathrm{AA}_{\mathrm{s}}\right)$ have been discovered in women with preeclampsia [52].

Thus the increased decidual $\mathrm{AT}_{1}$ expression in preeclampsia may be the initial step for a profound RAS activation. Furthermore, the presence of $\mathrm{AT}_{1}-\mathrm{AA}_{\mathrm{s}}$ is able to activate cells via the $\mathrm{AT}_{1}$ receptor and initiate signaling events that could contribute to development of preeclampsia. Thus, release of soluble flt- 1 can be triggered by angiotensin II stimulation, raising an imbalance between angiogenic vascular endothelial growth factors and antiangiogenic soluble factors [21]. Zhou et al. [21] have shown that the inhibition of $\mathrm{AT}_{1}$ administration of losartan or FK506 resulted in reduced SVEGFR-1. Thus, maternal SVEGFR-1 can be elevated not only by poor placentation but also by $\mathrm{AT}_{1}$ activation in which angiotensin II and $\mathrm{AT}_{1}-\mathrm{AA}_{\mathrm{s}}$ are potentially implicated.

\section{Placental Hypoxia and Ischemia}

Impaired trophoblast invasion and inadequate maternal spiral artery remodelling result in placental ischemia and hypoxia. It is unknown, however, whether abnormal placentation leads to systemic vascular dysfunction and the appearance of preeclampsia.

Defective trophoblast invasion and inadequate maternal spiral remodelling frequently result in intrauterine growth restriction or other complications of pregnancy (preterm labor e.g.) without preeclampsia even to normal full-term pregnancy [53]. Women living in high altitudes have an increased risk of developing preeclampsia [54], while cigarette smoking is associated with a reduced risk for preeclampsia [55]. Experiments in animals suggest that placental hypoxia contributes to preeclampsia by upregulating soluble antiangiogenic factors, inflammatory cytokines, downregulating angiogenic, and vasodilator factors [56].

Furthermore, in pregnant mice, an absence of 2-methoxyestradiol (2-ME), a natural metabolite of estradiol, results in a deficient of catechol-o-methyltransferase (COMT). These animals showed a preeclampsia-like phenotype [57]. The addition of 2-ME was shown to improve preeclampsia and suppress placental hypoxia and sflt-1 expression [57]. It is, however, unclear whether or not decreased COMT is the cause of the consequence of impaired placentation.

\section{References}

[1] J. C. Hauth, M. G. Ewell, R. J. Levine et al., "Pregnancy outcomes in healthy nulliparas who developed hypertension," $\mathrm{Ob}$ stetrics and Gynecology, vol. 95, no. 1, pp. 24-28, 2000.

[2] J. J. Walker, "Pre-eclampsia," Lancet, vol. 356, no. 9237, pp. 1260-1265, 2000.

[3] F. G. Cunningham, N. F. Gant, K. J. Leveno, L. C. Gilstrap, J. C. Hauth, and K. D. Wenstrom, "Hypertensive disorders in pregnancy," in Williams Obstetrics, pp. 567-618, McGraw-Hill, New York, NY, USA, 21st edition, 2001.

[4] P. Tubbergen, A. M. A. Lachmeijer, S. M. Althuisius, M. E. J. Vlak, H. P. Van Geijn, and G. A. Dekker, "Change in paternity: a risk factor for preeclampsia in multiparous women?" Journal of Reproductive Immunology, vol. 45, no. 1, pp. 81-88, 1999.

[5] J. R. Barton and B. M. Sibai, "Prediction and prevention of recurrent preeclampsia," Obstetrics and Gynecology, vol. 112, no. 2, pp. 359-372, 2008.

[6] M. S. Esplin, M. B. Fausett, A. Fraser et al., "Paternal and maternal components of the predisposition to preeclampsia," New England Journal of Medicine, vol. 344, no. 12, pp. 867872, 2001.

[7] K. Duckitt and D. Harrington, "Risk factors for pre-eclampsia at antenatal booking: systematic review of controlled studies," British Medical Journal, vol. 330, no. 7491, pp. 565-567, 2005.

[8] B. Sibai, G. Dekker, and M. Kupferminc, "Pre-eclampsia," Lancet, vol. 365, no. 9461, pp. 785-799, 2005.

[9] K. Koga, Y. Osuga, T. Tajima et al., "Elevated serum soluble fms-like tyrosine kinase 1 (sFlt1) level in women with hydatidiform mole," Fertility and Sterility, vol. 94, no. 1, pp. 305-308, 2010.

[10] Y. Bdolah, C. Lam, A. Rajakumar et al., "Twin pregnancy and the risk of preeclampsia: bigger placenta or relative ischemia?" American Journal of Obstetrics and Gynecology, vol. 198, no. 4, pp. 428.e1-428.e6, 2008.

[11] R. J. Levine, S. E. Maynard, C. Qian et al., "Circulating angiogenic factors and the risk of preeclampsia," New England Journal of Medicine, vol. 350, no. 7, pp. 672-683, 2004.

[12] A. S. R. Maharaj, T. E. Walshe, M. Saint-Geniez et al., "VEGF and TGF- $\beta$ are required for the maintenance of the choroid plexus and ependyma," Journal of Experimental Medicine, vol. 205, no. 2, pp. 491-501, 2008.

[13] H. F. Dvorak, "Vascular permeability factor/vascular endothelial growth factor: a critical cytokine in tumor angiogenesis and a potential target for diagnosis and therapy," Journal of Clinical Oncology, vol. 20, no. 21, pp. 4368-4380, 2002.

[14] M. Autiero, A. Luttun, M. Tjwa, and P. Carmeliet, "Placental growth factor and its receptor, vascular endothelial growth factor receptor-1: novel targets for stimulation of ischemic tissue revascularization and inhibition of angiogenic and inflammatory disorders," Journal of Thrombosis and Haemostasis, vol. 1, no. 7, pp. 1356-1370, 2003.

[15] R. L. Kendall, G. Wang, and K. A. Thomas, "Identification of a natural soluble form of the vascular endothelial growth factor receptor, FLT-1, and its heterodimerization with KDR," Biochemical and Biophysical Research Communications, vol. 226, no. 2, pp. 324-328, 1996. 
[16] M. Furuya, J. Ishida, I. Aoki, and A. Fukamizu, "Pathophysiology of placentation abnormalities in pregnancy-induced hypertension," Vascular Health and Risk Management, vol. 4, no. 6, pp. 1301-1313, 2008.

[17] R. L. Kendall and K. A. Thomas, "Inhibition of vascular endothelial cell growth factor activity by an endogenously encoded soluble receptor," Proceedings of the National Academy of Sciences of the United States of America, vol. 90, no. 22, pp. 1070510709, 1993.

[18] K. A. Wathén, E. Tuutti, U. H. Stenman et al., "Maternal serum-soluble vascular endothelial growth factor receptor-1 in early pregnancy ending in preeclampsia or intrauterine growth retardation," Journal of Clinical Endocrinology and $\mathrm{Me}$ tabolism, vol. 91, no. 1, pp. 180-184, 2006.

[19] C. P. Thomas, J. I. Andrews, and K. Z. Liu, "Intronic polyadenylation signal sequences and alternate splicing generate human soluble Flt1 variants and regulate the abundance of soluble Flt1 in the placenta," FASEB Journal, vol. 21, no. 14, pp. 3885-3895, 2007.

[20] S. Sela, A. Itin, S. Natanson-Yaron et al., "A novel humanspecific soluble vascular endothelial growth factor receptor 1 : cell type-specific splicing and implications to vascular endothelial growth factor homeostasis and preeclampsia," Circulation Research, vol. 102, no. 12, pp. 1566-1574, 2008.

[21] C. C. Zhou, S. Ahmad, T. Mi et al., "Autoantibody from women with preeclampsia induces soluble Fms-like tyrosine kinase-1 production via angiotensin type 1 receptor and calcineurin/nuclear factor of activated T-cells signaling," Hypertension, vol. 51, no. 4, pp. 1010-1019, 2008.

[22] S. Ahmad and A. Ahmed, "Elevated placental soluble vascular endothelial growth factor receptor-1 inhibits angiogenesis in preeclampsia," Circulation Research, vol. 95, no. 9, pp. 884$891,2004$.

[23] G. L. Semenza, “Targeting HIF-1 for cancer therapy," Nature Reviews Cancer, vol. 3, no. 10, pp. 721-732, 2003.

[24] R. J. Levine, C. Lam, C. Qian et al., "Soluble endoglin and other circulating antiangiogenic factors in preeclampsia," New England Journal of Medicine, vol. 355, no. 10, pp. 992-1005, 2006, Erratum in: New England Journal of Medicine, vol. 355, no. 17, p. 1840, 2006.

[25] H. He, V. J. Venema, X. Gu, R. C. Venema, M. B. Marrero, and R. B. Caldwell, "Vascular endothelial growth factor signals endothelial cell production of nitric oxide and prostacyclin through Flk-1/KDR activation of c-Src," Journal of Biological Chemistry, vol. 274, no. 35, pp. 25130-25135, 1999.

[26] P. Vallance, A. Leone, A. Calver, J. Collier, and S. Moncada, "Accumulation of an endogenous inhibitor of nitric oxide synthesis in chronic renal failure," Lancet, vol. 339, no. 8793, pp. 572-575, 1992.

[27] M. D. Savvidou, A. D. Hingorani, D. Tsikas, J. C. Frölich, P. Vallance, and K. H. Nicolaides, "Endothelial dysfunction and raised plasma concentrations of asymmetric dimethylarginine in pregnant women who subsequently develop pre-eclampsia," Lancet, vol. 361, no. 9368, pp. 1511-1517, 2003.

[28] L. A. Danielson, O. D. Sherwood, and K. P. Conrad, "Relaxin is a potent renal vasodilator in conscious rats," Journal of Clinical Investigation, vol. 103, no. 4, pp. 525-533, 1999.

[29] K. P. Conrad and M. C. Colpoys, "Evidence against the hypothesis that prostaglandins are the vasodepressor agents of pregnancy. Serial studies in chronically instrumented, conscious rats," Journal of Clinical Investigation, vol. 77, no. 1, pp. 236245, 1986.
[30] L. A. Danielson and K. P. Conrad, "Acute blockade of nitric oxide synthase inhibits renal vasodilation and hyperfiltration during pregnancy in chronically instrumented conscious rats," Journal of Clinical Investigation, vol. 96, no. 1, pp. 482-490, 1995.

[31] A. Jeyabalan, J. Novak, L. A. Danielson, L. J. Kerchner, S. L. Opett, and K. P. Conrad, "Essential role for vascular gelatinase activity in relaxin-induced renal vasodilation, hyperfiltration, and reduced myogenic reactivity of small arteries," Circulation Research, vol. 93, no. 12, pp. 1249-1257, 2003.

[32] J. M. Davison, V. Homuth, A. Jeyabalan et al., "New aspects in the pathophysiology of preeclampsia," Journal of the American Society of Nephrology, vol. 15, no. 9, pp. 2440-2448, 2004.

[33] B. N. Szlachter, J. Quagliarello, and R. Jewelewicz, "Relaxin in normal and pathogenic pregnancies," Obstetrics and Gynecology, vol. 59, no. 2, pp. 167-170, 1982.

[34] S. Y. Hsu, K. Nakabayashi, S. Nishi et al., "Activation of orphan receptors by the hormone relaxin," Science, vol. 295, no. 5555, pp. 671-674, 2002.

[35] D. Martin and K. P. Conrad, "Expression of endothelial nitric oxide synthase by extravillous trophoblast cells in the human placenta," Placenta, vol. 21, no. 1, pp. 23-31, 2000.

[36] M. S. Goligorsky, A. S. Budzikowski, H. Tsukahara, and E. Noiri, "Co-operation between endothelin and nitric oxide in promoting endothelial cell migration and angiogenesis," Clinical and Experimental Pharmacology and Physiology, vol. 26, no. 3, pp. 269-271, 1999.

[37] B. D. LaMarca, M. J. Ryan, J. S. Gilbert, S. R. Murphy, and J. P. Granger, "Inflammatory cytokines in the pathophysiology of hypertension during preeclampsia," Current Hypertension Reports, vol. 9, no. 6, pp. 480-485, 2007.

[38] S. Daher, F. Fonseca, O. G. Ribeiro, C. C. Musatti, and M. Gerbase-Delima, "Tumor necrosis factor during pregnancy and at the onset of labor and spontaneous abortion," European Journal of Obstetrics Gynecology and Reproductive Biology, vol. 83, no. 1, pp. 77-79, 1999.

[39] M. J. Kupferminc, A. M. Peaceman, T. R. Wigton, K. A. Rehnberg, and M. L. Socol, "Tumor necrosis factor- $\alpha$ is elevated in plasma and amniotic fluid of patients with severe preeclampsia," American Journal of Obstetrics and Gynecology, vol. 170, no. 6, pp. 1752-1759, 1994.

[40] G. S. Vince, P. M. Starkey, R. Austgulen, D. Kwiatkowski, and C. W. G. Redman, "Interleukin-6, tumour necrosis factor and soluble tumour necrosis factor receptors in women with preeclampsia," British Journal of Obstetrics and Gynaecology, vol. 102, no. 1, pp. 20-25, 1995.

[41] A. Estellés, J. Gilabert, S. Grancha et al., "Abnormal expression of type 1 plasminogen activator inhibitor and tissue factor in severe preeclampsia," Thrombosis and Haemostasis, vol. 79, no. 3, pp. 500-508, 1998.

[42] C. G. Solomon and E. W. Seely, "Hypertension in pregnancy a manifestation of the insulin resistance syndrome?" Hypertension, vol. 37, no. 2, pp. 232-239, 2001.

[43] S. J. Huang, C. P. Chen, F. Schatz, M. Rahman, V. M. Abrahams, and C. J. Lockwood, "Pre-eclampsia is associated with dendritic cell recruitment into the uterine decidua," Journal of Pathology, vol. 214, no. 3, pp. 328-336, 2008.

[44] C. J. Lockwood, P. Matta, G. Krikun et al., "Regulation of monocyte chemoattractant protein-1 expression by tumor necrosis factor- $\alpha$ and interleukin- $1 \beta$ in first trimester human decidual cells: Implications for preeclampsia," American Journal of Pathology, vol. 168, no. 2, pp. 445-452, 2006. 
[45] M. Paul, A. P. Mehr, and R. Kreutz, "Physiology of local reninangiotensin systems," Physiological Reviews, vol. 86, no. 3, pp. 747-803, 2006.

[46] T. Morgan, C. Craven, and K. Ward, "Human spiral artery renin-angiotensin system," Hypertension, vol. 32, no. 4, pp. 683$687,1998$.

[47] C. C. Zhou, S. Ahmad, T. Mi et al., "Angiotensin II induces soluble fms-like tyrosine kinase-1 release via calcineurin signaling pathway in pregnancy," Circulation Research, vol. 100, no. 1, pp. 88-95, 2007.

[48] J. Zheng, I. M. Bird, D. B. Chen, and R. R. Magness, “Angiotensin II regulation of ovine fetoplacental artery endothelial functions: interactions with nitric oxide," Journal of Physiology, vol. 565, no. 1, pp. 59-69, 2005.

[49] M. Hanssens, M. J. N. C. Keirse, B. Spitz, and F. A. Van Assche, "Angiotensin II levels in hypertensive and normotensive pregnancies," British Journal of Obstetrics and Gynaecology, vol. 98, no. 2, pp. 155-161, 1991.

[50] F. Herse, R. Dechend, N. K. Harsem et al., "Dysregulation of the circulating and tissue-based renin-angiotensin system in preeclampsia," Hypertension, vol. 49, no. 3, pp. 604-611, 2007.

[51] G. Wallukat, V. Homuth, T. Fischer et al., "Patients with preeclampsia develop agonistic autoantibodies against the angiotensin AT1 receptor," Journal of Clinical Investigation, vol. 103, no. 7, pp. 945-952, 1999.

[52] H. Stepan, R. Faber, N. Dornhöfer, B. Huppertz, A. Robitzki, and T. Walther, "New insights into the biology of preeclampsia," Biology of Reproduction, vol. 74, no. 5, pp. 772-776, 2006.

[53] B. C. Young, R. J. Levine, and S. A. Karumanchi, "Pathogenesis of preeclampsia," Annual Review of Pathology: Mechanisms of Disease, vol. 5, pp. 173-192, 2010.

[54] S. Zamudio, "High-altitude hypoxia and preeclampsia," Frontiers in Bioscience, vol. 12, pp. 2967-2977, 2007.

[55] X. Xiong, F. L. Wang, S. T. Davidge et al., "Maternal smoking and preeclampsia," Journal of Reproductive Medicine for the Obstetrician and Gynecologist, vol. 45, no. 9, pp. 727-732, 2000.

[56] S. A. Karumanchi and Y. Bdolah, "Hypoxia and sFlt-1 in preeclampsia: the "chicken-and-egg" question," Endocrinology, vol. 145, no. 11, pp. 4835-4837, 2004.

[57] K. Kanasaki, K. Palmsten, H. Sugimoto et al., "Deficiency in catechol-O-methyltransferase and 2-methoxyoestradiol is associated with pre-eclampsia," Nature, vol. 453, no. 7198, pp. 1117-1121, 2008. 


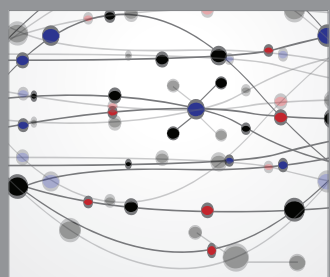

The Scientific World Journal
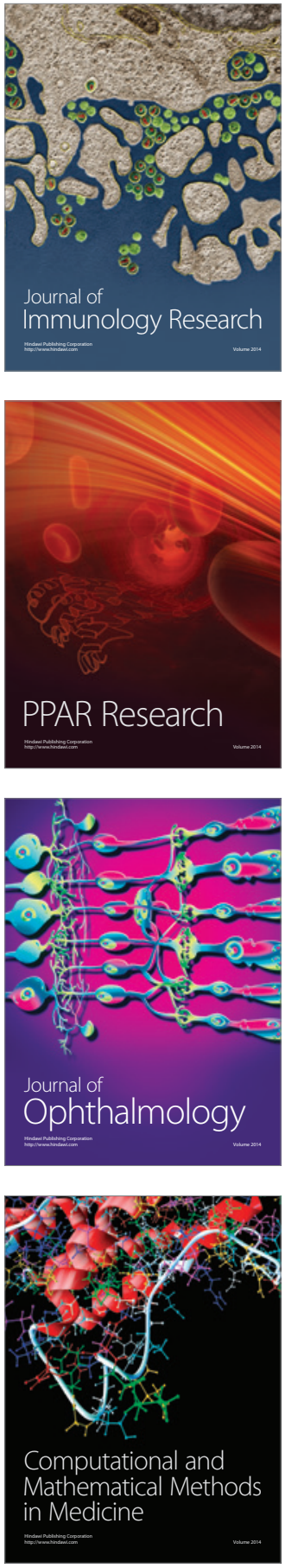

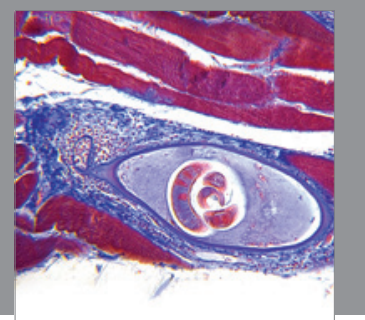

Gastroenterology

Research and Practice
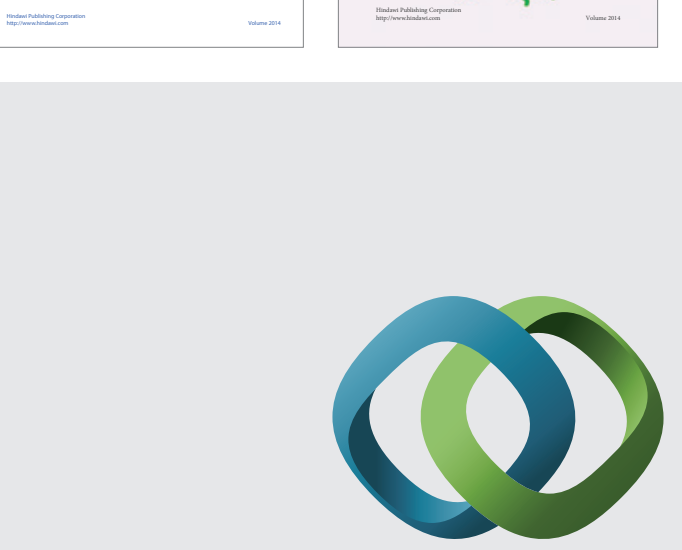

\section{Hindawi}

Submit your manuscripts at

http://www.hindawi.com
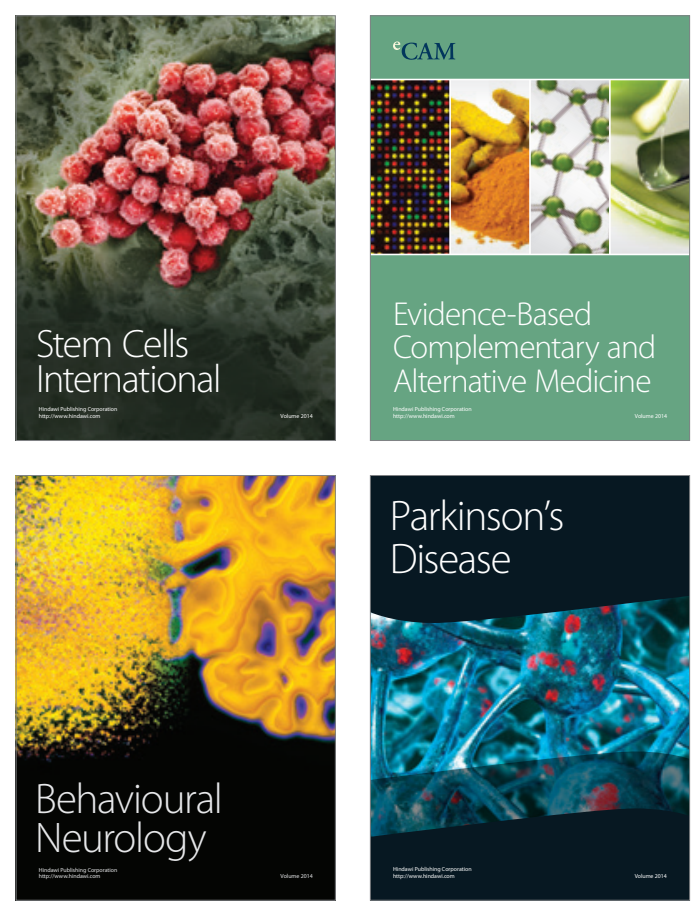

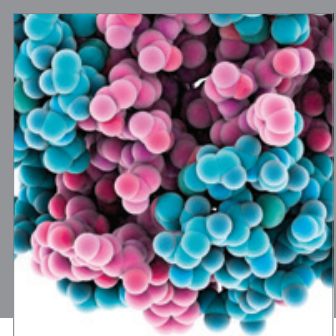

Journal of
Diabetes Research

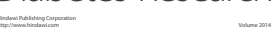

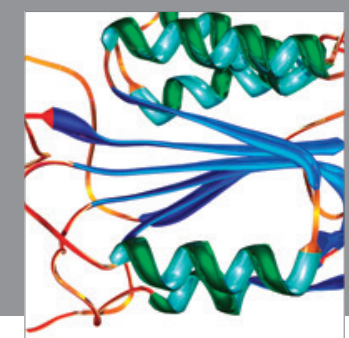

Disease Markers
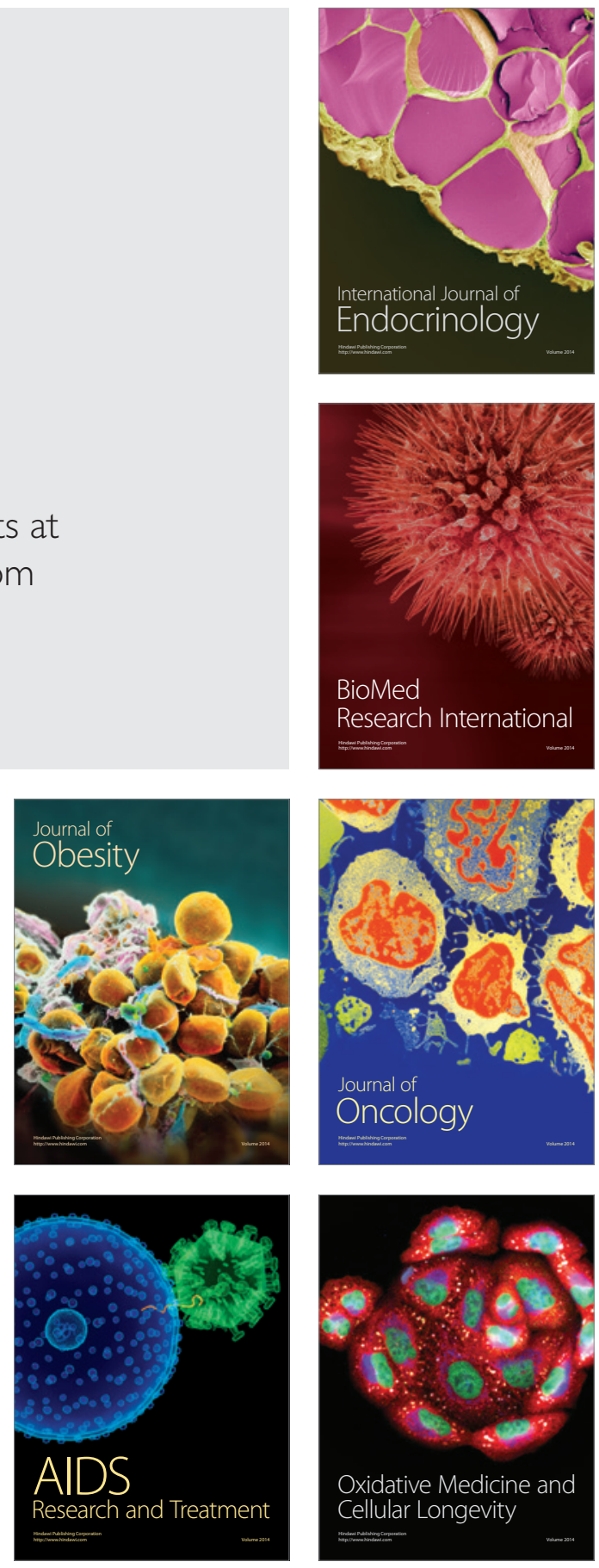